\title{
THE IMPACT OF THE NUMBER OF TEARS IN PATIENT- SPECIFIC STANFORD TYPE B AORTIC DISSECTING ANEURYSM: CFD SIMULATION*
}

\author{
WAN NAIMAH \\ WAN AB NAIM \\ Department of Biomedical Engineering, Faculty of \\ Engineering, University Malaya, \\ Kuala Lumpur, 50603 \\ Malaysia \\ wan_88_na@yahoo.com.my \\ POO BALAN \\ GANESAN \\ Department of Mechani cal Engineering, Faculty of \\ Engineering, University Malaya, \\ Kuala Lumpur, 50603, \\ Malaysia \\ poo_ganesan@um.edu.my \\ ZHONGHUA SUN \\ Discipline of Medical Imaging, Department of \\ Imaging and Applied physics, Curtin University \\ Perth, 6845, Australia \\ Z.Sun@exchange.curtin.edu.au \\ KAHAR OSMAN \\ Faculty of Mechani cal Engineering, University \\ Teknol ogi Malaysia UTM \\ Skudai, Johor, 81310 , \\ Malaysia \\ kahar@fkm.utm.my \\ EINLY LIM \\ Department of Biomedical Engineering, Faculty of \\ Engineering, University Malaya, \\ Kuala Lumpur, 50603, \\ Malaysiaeinly_lim@um.edu.my
}


It is believed that the progression of Stanford type B aortic dissection is closely associated with vascular geometry and hemodynamic parameters. The hemodynamic differences owing to the presence of greater than two tears have not been explored. The focus of the present study is to investigate the impact of an additional reentry tear on the flow, pressure and wall shear stress distribution in the dissected aorta. A 3D aorta model with one entry and one reentry tear was generated from computed tomography (CT) angiographic images of a patient with Stanford Type B aortic dissection. To investigate the hemodynamic effect of more than two tear locations, an additional circular reentry tear was added $24 \mathrm{~mm}$ above the original reentry tear. Our simulation results showed that the presence of an additional reentry tear provided an extra return path for blood back to the true lumen during systole, and an extra outflow path into the false lumen during diastole. The presence of this additional path led to a decrease in the false lumen pressure, particularly at the distal region. Meanwhile, the presence of this additional tear cause no significant difference on the time average wall shear stress (TAWSS) distribution except at regions adjacent to reentry tear 2. Moderate and concentrated TAWSS was observed at the bottom region of this additional tear which may lead to further extension of the tear distally.

Keywords: Aortic dissection; Patient-specific; Computational fluid dynamic

\section{Introduction}

Cardiovascular diseases are the major cause of death in both developed and developing countries ${ }^{1}$.Aortic dissection is one of the most common cardiovascular diseases. Aortic dissection can be a life-threatening event which is characterized by splitting of the aortic wall by high blood pressure entering the media through an intimomedial entrance tear. There is an estimated worldwide prevalence of aortic dissection, which is 0.5-2.95 per 100,000 people per year ${ }^{2}$. The formation of the aortic dissection starts with the tear in the aortic intima layer. Blood flows through the tear and subsequently causes the layer to divide into true and false lumens ${ }^{3,4}$. Dissections may propagate either in distal or proximal direction from the entry tear ${ }^{5}$. The blood from the false lumen may reenter the true lumen anywhere along the course of the dissection. Differentiation between true and false lumens is important in the planning of percutaneous treatment with endovascular stent grafts or surgical repair of aortic dissection ${ }^{6,7}$. It is crucial to identify the lumen of origin in major branch vessels such as coronary, carotid, renal and mesenteric arteries before treatment because viscera supplied by the false lumen are at risk when the false lumen is spontaneously or surgically occluded ${ }^{8}$.

Based on Erbel et al ${ }^{1}$, several system of classification for aortic dissection have been developed including the Stanford, Debakey and Svensson systems. According to the Stanford system, aortic dissection can be classified into Type A if it involves the ascending aorta and Type B if it involves the descending aorta only ${ }^{1,5,9,10}$. On the other hand, the Debakey system is further classified into three systems with Type 1 involving the entire aorta, Type 2 affecting the ascending aorta only and Type 3 affecting the descending aorta only ${ }^{11,12}$. The Stanford system is widely used by the physicians as a simple guide to decide the urgency of a surgical treatment, while the Debakey system is useful to understand the clinical behavior of aortic dissection ${ }^{9}$. 
Accepted manuscript of an article published as: Naim, Wan and Ganesan, Poo and Sun, Zhonghua and Osman, Kahar and Lim, Einly. 2014. The impact of the number of tears in patient-specific Stanford type B aortic dissecting aneurysm: CFD simulation.

Journal of Mechanics in Medicine and Biology. 14 (2): 1450017 (20 p.). DOI: 10.1142/S0219519414500171

The focus of the present study is Type B aortic dissection, which has a high follow-up mortality rate ${ }^{10}$. The optimal treatment strategy for type $\mathrm{B}$ aortic dissection remains controversial ${ }^{13}$. Due to the high mortality rate associated with the surgical treatment, medical treatment is usually chosen for uncomplicated cases of the type B aortic dissection ${ }^{13,14}$. However, if left untreated, about $30 \%$ at clinical presentation suffers from hemodynamic instability conditions with a high risk of mortality ${ }^{13}$. Endovascular techniques have become an alternative option in the treatment of Type B dissection ${ }^{15}$

Czermak et al ${ }^{5}$ stated that $20 \%-50 \%$ of patients who survived from acute aortic dissection develop aneurysms. Several factors have been associated with the development and progression of aortic dissection, including hypertension ${ }^{16,17}$, genetic factors and connective tissue diseases ${ }^{4,16}$, old age, previous repair of aortic aneurysm or dissection ${ }^{9}$, hemodynamic effects, vascular geometry, mechanical properties and composition of the aorta wall ${ }^{4}$. It has been suggested to do follow up measurement of the aortic diameter to predict dilation and rupture ${ }^{18}$. However, Rudenick et al ${ }^{3}$ reported that dilation is mainly triggered by hemodynamic parameters, and geometry of false and true lumen. According to Nabaie et al ${ }^{19}$, hemodynamics play an important role in the pathogenesis, thrombosis, and destabilization or rupture of the aneurysm. Medical imaging modalities, such as computed tomography (CT) scan can provide excellent anatomical structures of the true lumen, false lumen as well as the tear in aortic dissection ${ }^{20}$, however it lacks the ability to provide information about the hemodynamic effect ${ }^{20}$. Thus, computational fluid dynamics (CFD) has been used for the analysis of hemodynamic changes of the blood vessel ${ }^{20}$. CFD allows for an early detection of abnormal changes and improves the understanding of the hemodynamic result in aortic dissection study, so that the prevention of potential complications and better patient management can be achieved ${ }^{20}$

In the CFD study by Cheng et al. ${ }^{21}$, it has been shown that geometry plays an important role in determining the nature of the hemodynamic patterns. Increased shear stress and chaotic flow was observed in the narrowed arterial lumen. In another study, Tse et al. $^{4}$ showed that vortices occurred in the thoracoabdominal aorta in the dissection case due to changes in the cross sectional area and curvature along the vessel. Examination of the vorticity field is able to provide an insight into the fluid dynamics of cardiovascular disease ${ }^{22}$. The information of normal and pathological physiology flow extracted through the experimental and simulation studies can be used to evaluate the cardiac status of a patient ${ }^{23}$.

To date, numerous experimental and numerical studies have been carried out to investigate the effect of tear size, location, and patency within the false lumen on regional hemodynamics. Using ex vivo experiments performed on different dissection models, Tsai et al ${ }^{24}$ demonstrated that diastolic false lumen pressure substantially increases by decreasing the proximal tear size and removing the distal tear, which are both important determinants of inflow and outflow. Similarly, Cheng et al. ${ }^{21}$ proposed that the location and size of the proximal and distal tear determines the quantity of the blood flowing into false lumen which in turn affects false lumen expansion and rupture. In Tang et al ${ }^{25}$ and Karmonik et al ${ }^{26}$, they evaluated the variation of the tear number with and without the presence of the reentry tear. Tang et $\mathrm{al}^{25}$ found that the pulsating pressure waveform for closed end dissection is a few percent higher than that observed in the open end dissection. In addition Karmonik et al ${ }^{26}$ also stated that the false lumen outflow restriction may increase the false lumen pressure. 
Despite the existence of various literature studies, the hemodynamic differences owing to the presence of greater than two tears have not been explored. In a clinical study performed by Quint et al ${ }^{27}$, different number of tears were found for 52 different patients with 10 patients presenting with single tear, 22 patients with 2 tears, 9 patients with 3 tears, 9 patients with 4 tears, one patient with 5 and 7 tears, respectively. The study shows that a large number of aortic dissection patient with more than two tears. The identification of number of tears may be helpful in predicting a pressure differential between the true and false lumens, in predicting outcome without treatment, and in assisting treatment planning ${ }^{27}$. Studies have shown that communications between the true and false lumens below the entry tear may help prevent true lumen collapse and identification of multiple distal communications between the lumens may be a useful predictor for certain patients ${ }^{27}$. Therefore, the aim of the present study is to investigate the impact of an additional reentry tear which is in total three tears, on the flow, pressure and wall shear stress distribution in the dissecting aorta.

\section{Methodology}

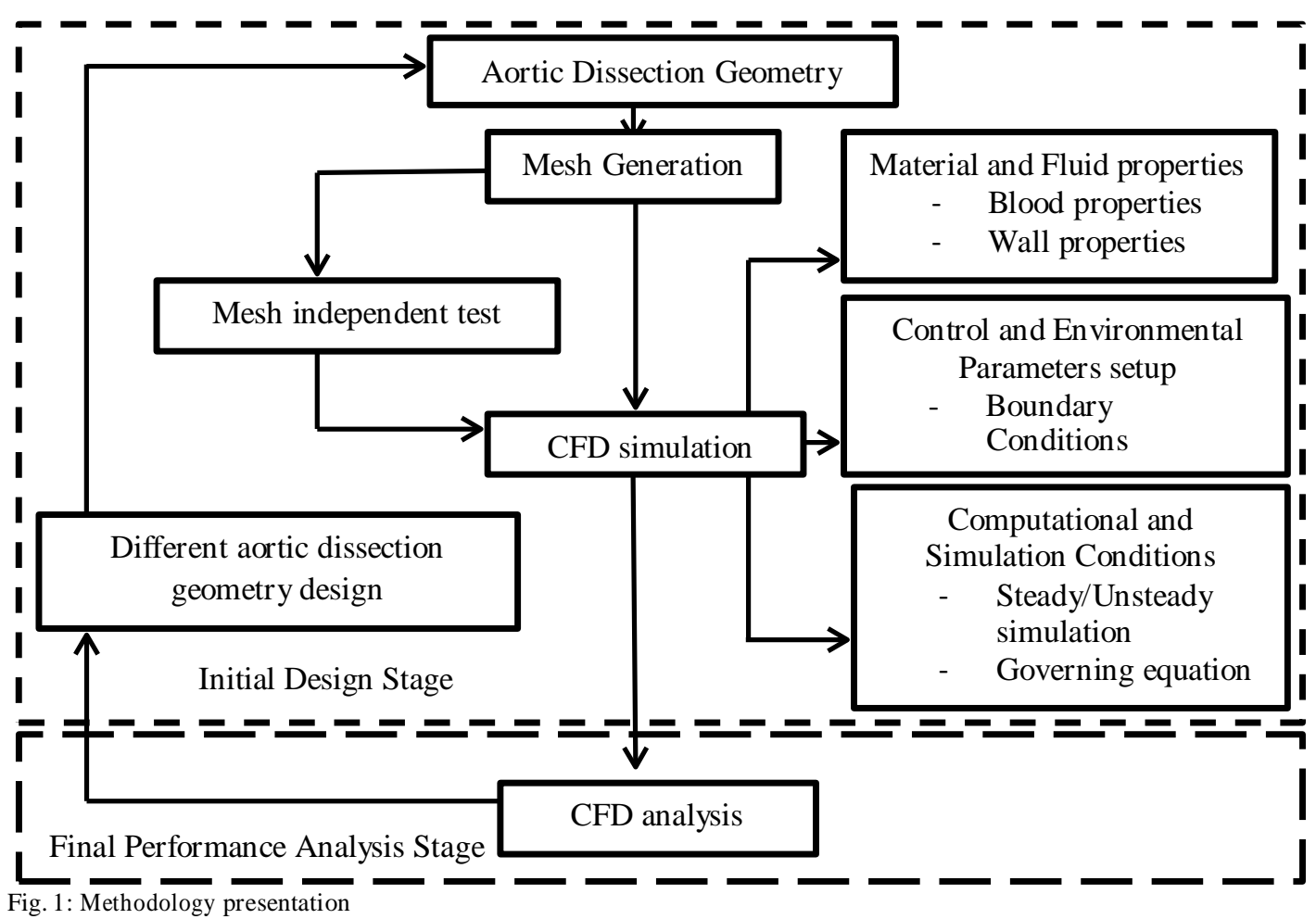

Fig 1 shows the flow chart presentation of the methodology based on the example given by Wong et $\mathrm{al}^{20}$. The CFD analysis was carried out in two stages consisting of the initial design stage and the final performance analysis stage ${ }^{20}$. 


\subsection{Model geometry}

A patient diagnosed with Stanford Type B aortic dissecting aneurysm was selected and the patient's computed tomography $(\mathrm{CT})$ data was post processed to generate a 3D aorta model, as shown in Fig. 2a (Case 1). To investigate the effect of more than two tears on the hemodynamic, an additional circular reentry tear was added $24 \mathrm{~mm}$ above the original reentry tear. A total of three cases were studied: (i) original geometry with an entry and a reentry tear (Case 1, Fig. 2a); (ii) original geometry with an additional reentry tear of 10 $\mathrm{mm}$ diameter (Case 2, Fig. 2b); and (iii) original geometry with an additional reentry tear of $16 \mathrm{~mm}$ diameter (Case 3, Fig. 2c). The diameter of the additional reentry tear is comparable to that reported by Quint et al $^{27}$.

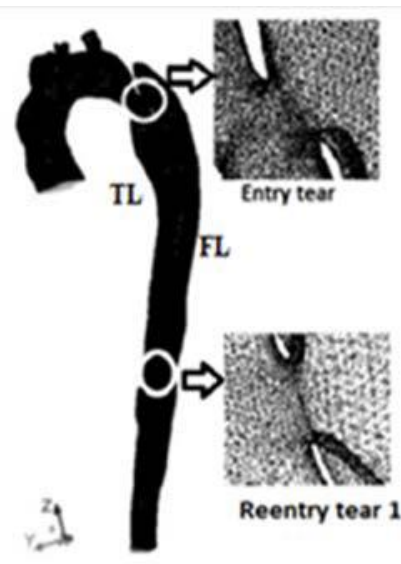

(a)

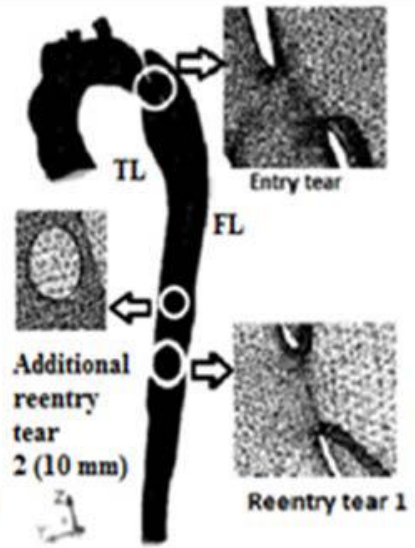

(b)

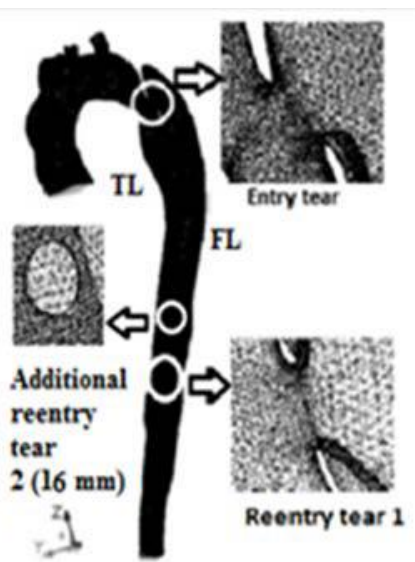

(c)

Fig. 2: 3D reconstructed model of aortic dissecting aneurysm. (a) Case 1: original geometry with 1 entry and 1 reentry tear; (b) Case 2: original geometry with an additional reentry tear of $10 \mathrm{~mm}$ diameter; and (c) Case 3: original geometry with an additional reentry tear of $16 \mathrm{~mm}$ diameter. Note that TL is the true lumen whereas FL is the false lumen.

\section{2. $\quad$ Model settings}

The blood was assumed to be homogenous, incompressible and Newtonian with a dynamic viscosity of 0.00371 Pa.s and a density of $1060 \mathrm{~kg} / \mathrm{m}^{3}{ }^{4}$. Since blood demonstrates non-Newtonian behavior at shear rate lower than $100 \mathrm{~s}^{-1}$, the assumption of Newtonian flow in the aorta is reasonable as shear rate in large arteries (e.g. aorta) is greater than $100 \mathrm{~s}^{-1} 4,28$. According to Tse et $\mathrm{al}^{4}$ and Cheng et $\mathrm{al}^{21}$, blood flow is usually assumed laminar in large vessels as the mean flow velocity and the Reynolds number is low. For a pulsatile, unsteady flow, turbulence occurs at a Reynolds number much larger than that expected for a steady flow due to a more stable accelerating flow and a more unstable decelerating flow. Flow can be assumed to be laminar if the maximum Reynolds number $\left(\operatorname{Re}_{\max }\right)$ is less than the critical Reynolds number $\left(\operatorname{Re}_{\mathrm{c}}\right)^{4,29,30}$. The critical Reynolds number $\left(\mathrm{Re}_{\mathrm{c}}\right)$ or also called the transition Reynolds number for unsteady flow takes the form of $\operatorname{Re}_{\mathrm{c}}=k \times$ Wormersley number ${ }^{31}$. The approximation of the $k$ value is based on the experimental study on canine aortas by Nerem et $\mathrm{al}^{31}$ with $k$ being the constant of proportionality ranging from 250 to 1000 . 
The critical Reynolds number, $\operatorname{Re}_{c}$ calculated in this study based on the average Wormersley numberranges from 5150 to 20600 for Case 1, 4850 to 19400 for Case 2 and 4930 to 19700 for Case 3, respectively. Meanwhile, the maximum Reynolds number $\left(\mathrm{Re}_{\max }\right)$ in our model (occurring at the exit tear) for Cases 1, 2 and 3 are 4820, 4530 and 4590 , respectively. Since the maximum Reynolds number, $\mathrm{Re}_{\max }$ for our models are lower than this range of critical Reynolds number, $\mathrm{Re}_{\mathrm{c}}$, the flow in our model can be assumed to be laminar. The average Reynolds numbers $\left(\mathrm{Re}_{\mathrm{ave}}\right)$ along the vessel based on the average flow velocity $\left(\mathrm{V}_{\text {ave }}\right)$ and the average hydraulic diameter $\left(\mathrm{D}_{\mathrm{h} \text {,ave }}\right)$ at peak systole for Cases 1, 2 and 3 are 3200, 2910, and 2910 respectively as shown in Tables 1-3.. The aortic wall was assumed to be rigid and no-slip condition was applied at the wall.

Table 1: The Reynolds number and Wormersley number at various vessel cross sections for Case 1

\begin{tabular}{lccccc}
\hline \multicolumn{1}{c}{ Section } & $\begin{array}{c}\text { Velocity } \\
(\mathrm{mm} / \mathrm{s})\end{array}$ & $\begin{array}{c}\text { Area } \\
\left(\mathrm{mm}^{2}\right)\end{array}$ & $\begin{array}{c}\text { Hydraulic } \\
\text { diameter }(\mathrm{mm})\end{array}$ & $\begin{array}{c}\text { Reynolds } \\
\text { number }\end{array}$ & $\begin{array}{c}\text { Wormersley } \\
\text { number }\end{array}$ \\
\hline Inlet & 174 & 1490 & 43.5 & 2160 & 29.2 \\
Midway Ascending aorta & 213 & 1290 & 40.5 & 2480 & 27.2 \\
Aortic arch & 175 & 1400 & 42.2 & 2110 & 28.3 \\
Exit aortic arch (TL) & 270 & 810 & 32.1 & 2470 & 21.5 \\
Exit aortic arch (FL) & 175 & 1040 & 36.4 & 1820 & 24.4 \\
Entry tear & 494 & 500 & 25.2 & 3560 & 16.9 \\
Reentry tear 1 & 1020 & 210 & 16.5 & 4820 & 11.1 \\
Descending aorta (TL) & 322 & 210 & 16.2 & 1490 & 10.9 \\
Descending aorta (FL) & 227 & 710 & 30.0 & 1940 & 20.1 \\
Outlet & 573 & 480 & 24.6 & 4030 & 16.5 \\
Average & 364 & & 30.7 & 3200 & 20.6 \\
\hline
\end{tabular}

Table 2: The Reynolds number and Wormersley number at variou s vessel cross sections for Case 2

\begin{tabular}{|c|c|c|c|c|c|}
\hline Section & $\begin{array}{l}\text { Velocity } \\
(\mathrm{mm} / \mathrm{s})\end{array}$ & $\operatorname{Area}\left(\mathrm{mm}^{2}\right)$ & $\begin{array}{c}\text { Hydraulic } \\
\text { diameter }(\mathrm{mm})\end{array}$ & $\begin{array}{c}\text { Reynolds } \\
\text { number }\end{array}$ & $\begin{array}{c}\text { Wormersley } \\
\text { number }\end{array}$ \\
\hline Inlet & 174 & 1490 & 43.5 & 2160 & 29.2 \\
\hline Midway Ascending aorta & 213 & 1290 & 40.5 & 2470 & 27.2 \\
\hline Aortic arch & 175 & 1400 & 42.2 & 2110 & 28.3 \\
\hline Exit aortic arch (TL) & 270 & 810 & 32.1 & 2480 & 21.5 \\
\hline Exit aortic arch (FL) & 183 & 1060 & 36.7 & 1920 & 24.6 \\
\hline Entry tear & 493 & 500 & 25.2 & 3560 & 16.9 \\
\hline Reentry tear 1 & 963 & 210 & 16.4 & 4530 & 11.1 \\
\hline Reentry tear 2 & 311 & 77 & 10.0 & 890 & 6.7 \\
\hline Descending aorta (TL) & 295 & 210 & 16.2 & 1370 & 10.9 \\
\hline Descending aorta (FL) & 235 & 710 & 30.0 & 2010 & 20.1 \\
\hline Outlet & 572 & 480 & 24.6 & 4030 & 16.5 \\
\hline Average & 353 & & 28.9 & 2910 & $\underline{19.4}$ \\
\hline
\end{tabular}


Table 3: The Reynolds number and Wormersley number at various vessel cross sections for Case 3

\begin{tabular}{|c|c|c|c|c|c|}
\hline Section & $\begin{array}{l}\text { Velocity } \\
(\mathrm{mm} / \mathrm{s})\end{array}$ & $\operatorname{Area}\left(\mathrm{mm}^{2}\right)$ & $\begin{array}{c}\text { Hydraulic } \\
\text { diameter }(\mathrm{mm})\end{array}$ & $\begin{array}{c}\text { Reynolds } \\
\text { number }\end{array}$ & $\begin{array}{c}\text { Wormersley } \\
\text { number }\end{array}$ \\
\hline Inlet & 174 & 1490 & 43.5 & 2160 & 29.2 \\
\hline Midway Ascending aorta & 213 & 1290 & 40.5 & 2470 & 27.2 \\
\hline Aortic arch & 175 & 1400 & 42.2 & 2110 & 28.3 \\
\hline Exit aortic arch (TL) & 261 & 810 & 32.1 & 2390 & 21.5 \\
\hline Exit aortic arch (FL) & 182 & 1060 & 36.7 & 1910 & 24.6 \\
\hline Entry tear & 500 & 500 & 25.2 & 3600 & 16.9 \\
\hline Reentry tear 1 & 973 & 210 & 16.5 & 4590 & 11.1 \\
\hline Reentry tear 2 & 226 & 190 & 15.7 & 1020 & 10.5 \\
\hline Descending aorta (TL) & 296 & 210 & 16.2 & 1370 & 10.9 \\
\hline Descending aorta (FL) & 234 & 710 & 30.0 & 2010 & 20.1 \\
\hline Outlet & 573 & 480 & 24.6 & 4030 & 16.5 \\
\hline Average & 346 & & 29.4 & 2910 & $\underline{19.7}$ \\
\hline
\end{tabular}

\subsection{Boundary Conditions}

A flat velocity profile with a pulsatile flow applied at the entrance of the ascending aorta has been taken from Tse et al ${ }^{4}$ and Olufsen et al ${ }^{32}$ as shown in Fig. 3 (a). The use of a flat velocity profile at the aortic inlet is justified based on Wen et al ${ }^{28}$ and Shahcheraghi et al ${ }^{33}$ in which in-vivo measurements using the hot film anemometry technique on various animal models have been carried out. The outlets for the flow are at three aortic arch branches with different outlet diameter, i.e. left subclavian artery, left common carotid artery and brachiochepalic artery and at the descending aorta. The pulsatile inlet velocity profile was scaled and applied at the outlet of each of the three aortic arch branches with an assumption that five percent of the flow volume is diverted to each branch outlet, as observed in a healthy aorta ${ }^{4,32}$, see Fig. $3 \mathrm{c}$. Note that negative velocity refers to the outlet condition. On the other hand, a pulsatile pressure waveform as shown in Fig. 3 (b) (adapted from Tse et al ${ }^{4}$ and Olufsen et al ${ }^{32}$ ) was applied at the exit of the descending aorta.

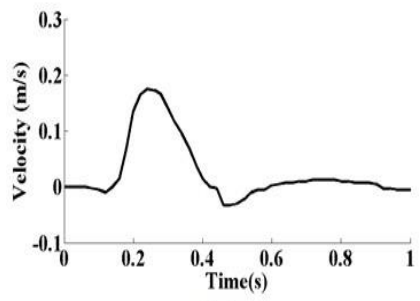

(a)

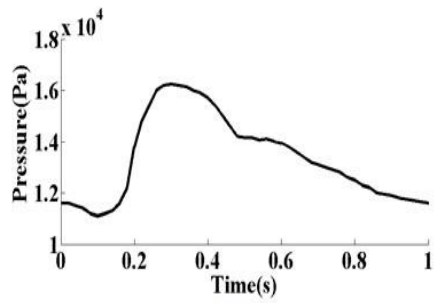

(b)

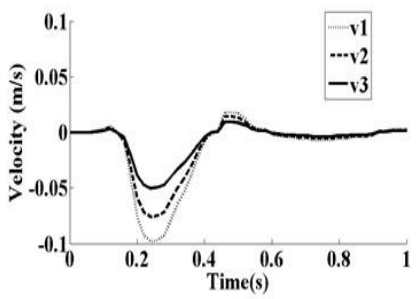

(c)

Fig. 3: Inlet and outlet boundary conditions: (a) Pulsatile inlet velocity profile; (b) Pulsatile outlet pressure profile; (c) Pulsatile outlet velocity profile at the three aortic aortic branches, i.e. left subclavian artery (v1), left common carotid artery (v2) and brachiochepalic artery (v3). 
Accepted manuscript of an article published as: Naim, Wan and Ganesan, Poo and Sun, Zhonghua and Osman, Kahar and Lim, Einly. 2014. The impact of the number of tears in patient-specific Stanford type B aortic dissecting aneurysm: CFD simulation.

Journal of Mechanics in Medicine and Biology. 14 (2): 1450017 (20 p.). DOI: 10.1142/S0219519414500171

8 Wan Ab Naim, W.N. et al

\subsection{Governing equations}

Mass continuity ("Eq. (1)") and Navier Stokes equation ("Eq. (2)") was used to govern the blood flow in the current study.

$\nabla . \vec{v}=0$.

$\frac{\partial}{\partial t}(p \vec{v})+\rho(\vec{v}, \nabla) \vec{v}=-\nabla p+\rho \vec{g}+\mu \nabla^{2} \vec{v}$

The symbol $\vec{v}$ is the velocity vector, $\mathrm{p}$ is the pressure, $\rho$ is the density and $\mu$ is the viscosity.

\subsection{Numerical Methods}

The finite volume method in the ANSYS FLUENT package (ANSYS, Inc.) was used to run the simulations. Discretisation of "Eqs. (1) and (2)" was achieved using the Second Order Upwind Scheme. The PISO (Pressure Implicit with Splitting of Operators) algorithm was used for the coupling of the pressure-velocity terms.

A steady state solution at the maximum flow rate was first obtained which was then used as an initial condition for unsteady solution. The periodic natures of the flow based on 4 cardiac cycles were simulated. All the results presented in the current study from the $4^{\text {th }}$ cardiac cycle. During the post processing stage, the results were taken at two time instants, i.e. at $\mathrm{t}=3.25$ (peak systole) and at $\mathrm{t}=3.47 \mathrm{~s}$ (early diastole) to represent the systolic and diastolic phase.

\subsection{Mesh Independent Test}

The geometry was meshed with 4 nodes tetrahedral elements using Meshing tool in ANSYS CFD (ANSYS, Inc.), with a total number of 250841 elements. The spatial localized mesh independent test was applied in Case 1, where the numbers of elements were increased at the reentry tear 1 region (an increase of 130029 numbers of elements). In addition, global refinement has been performed to the whole geometry in Case 1 . This mesh has 1.7 million numbers of elements, which is about seven times higher than that of the original mesh. Wall shear stress (WSS) and pressure values from the both local and global refinements at $\mathrm{t}=3.20 \mathrm{~s}$ and $\mathrm{t}=3.38 \mathrm{~s}$ are shown in Table 4 and Table 5, respectively.

Table 4: Local and global refinement of wall shear stress at $\mathrm{t}=3.20 \mathrm{~s}$ and $\mathrm{t}=3.38 \mathrm{~s}$

\begin{tabular}{|c|c|c|c|c|}
\hline \multirow[t]{2}{*}{ Mesh } & \multicolumn{2}{|c|}{ Time $3.20 \mathrm{~s}$} & \multicolumn{2}{|c|}{ Time $3.38 \mathrm{~s}$} \\
\hline & Re-entry tear 1 & Entry tear & Re-entry tear 1 & Entry tear \\
\hline (a) 250841 mesh elements $(\mathrm{Pa})$ & 35.5 & 13.3 & 28.3 & 1.8 \\
\hline $\begin{array}{l}\text { (b) Local refinement }(380870) \\
\text { (Pa) }\end{array}$ & 32.8 & & 29.1 & \\
\hline $\begin{array}{l}\text { (c) Global refinement } \\
(1716400)(\mathrm{Pa})\end{array}$ & 33.2 & 15.2 & 27.9 & 1.73 \\
\hline Percentage difference (a) and (b) & $7.6 \%$ & & $2.7 \%$ & \\
\hline Percentage difference (a) and (c) & $1.3 \%$ & $12.6 \%$ & $1.3 \%$ & $1.6 \%$ \\
\hline Percentage difference (b) and (c) & $1.2 \%$ & & $4.1 \%$ & \\
\hline
\end{tabular}


Table 5: Local and global refinement of pressure at $\mathrm{t}=3.20 \mathrm{~s}$ and $\mathrm{t}=3.38 \mathrm{~s}$

\begin{tabular}{|c|c|c|c|c|}
\hline \multirow[t]{2}{*}{ Mesh } & \multicolumn{2}{|c|}{ Time $3.20 \mathrm{~s}$} & \multicolumn{2}{|c|}{ Time $3.38 \mathrm{~s}$} \\
\hline & Re-entry tear 1 & Entry tear & Re-entry tear 1 & Entry tear \\
\hline (a) 250841 mesh elements $(\mathrm{kPa})$ & 16.3 & 17.1 & 15.1 & 14.7 \\
\hline (b) Local refinement (380870) & 16.4 & & 15.0 & \\
\hline$(\mathrm{kPa})$ & & & & \\
\hline $\begin{array}{l}\text { (c) Global refinement } \\
(1716400)(\mathrm{kPa})\end{array}$ & 16.5 & 17.2 & 14.9 & 14.4 \\
\hline Percentage difference (a) and (b) & $0.1 \%$ & & $0.9 \%$ & \\
\hline Percentage difference (a) and (c) & $0.9 \%$ & $0.8 \%$ & $1.5 \%$ & $2.0 \%$ \\
\hline Percentage difference (b) and (c) & $0.7 \%$ & & $0.6 \%$ & \\
\hline
\end{tabular}

The WSS distribution is similar for all three meshes conditions. The differences between the 250841 number of mesh (Mesh (a)) with the local refinement (Mesh (b)) and global refinement (Mesh (c)) are small being less than $5.0 \%$. Exception seen for WSS of Mesh (a) and Mesh (c) at entry tear 1 (Table 1) with a difference of $12.6 \%$. To investigate this, the pressure difference has been checked and found to be less than $1.0 \%$. Therefore, the original mesh settings (with 250841 numbers of elements) were used for the present simulations to compromise between the accuracy and the limitation of the computer resources. The number of elements for Cases 2 and 3 were 251176 and 250964 respectively. A workstation with Intel Core i 7 with $3.9 \mathrm{GHz}$ speed and 12 Gbyte memory was used in the current study. Based on the computer processing capability, an optimum total number of mesh elements has been used without significantly affecting the results presented.

\subsection{Numerical validation}

The mass flow rate at the aortic inlet is consistent with the sum of the mass flow out at the four outlets ( 3 branches at the proximal region and descending aorta), i.e. $1.04 \times 10^{-4} \mathrm{~kg} / \mathrm{s}$. This shows that the present simulation obeyed the mass conservation law.

\section{Results}

\subsection{Flow Distribution}

Fig. 4 shows the flow distribution using the velocity vector plot at the regions near the entry tear at the proximal location and the reentry tears at the distal location of the true and false lumens during both systole and diastole. The flow is accelerated and no flow separation is observed during systole. It can be observed that the blood from the aortic arch flows from the true lumen to the false lumen through the entry tear in all cases relatively at a high velocity. At the same time, blood flows from the proximal to the distal part in both the true and false lumens. At the distal region of the vessel, blood returns to the true lumen through reentry tear 1 (for all cases) and 2 (for Case $2 \& 3$ ). Highest velocity is found at the bottom region of the reentry tear 1 in all cases. 
During the diastolic phase, recirculation and retrograde flow is observed in all cases, with obvious recirculation flow everywhere near the tears. The recirculation flow rotates in both the clockwise and the counterclockwise directions. As compared to the systolic phase, directionally opposite blood flow occurs. Blood enters the false lumen from the true lumen through reentry 1 (for all cases) and 2 (for Case $2 \& 3$ ), with the highest velocity at the bottom region of the reentry tear 1 . It then flows up to the proximal region and return to the true lumen through the entry tear.

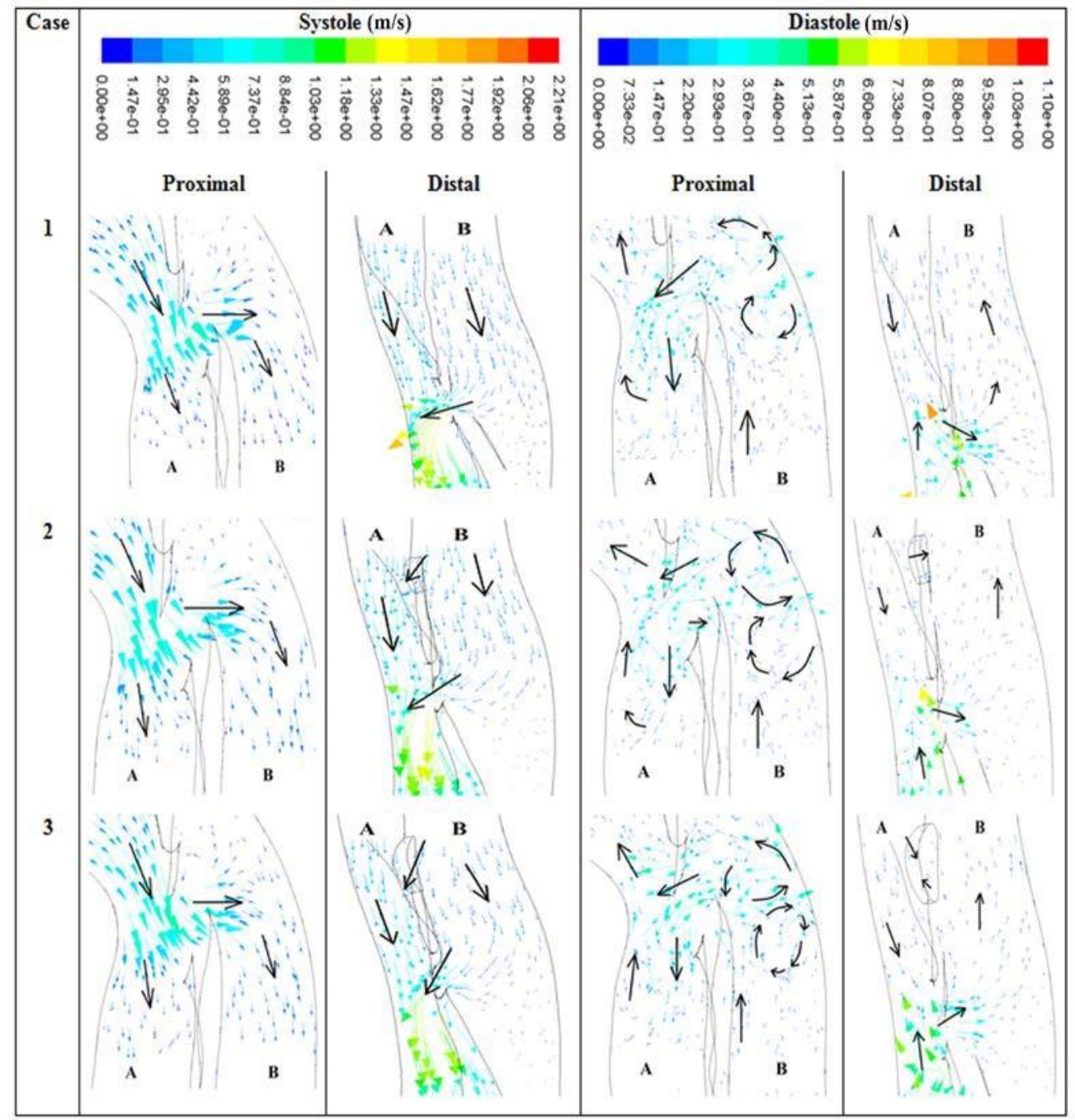

Fig. 4: The flow distribution at the proximal (near the entry tear) and distal locations (near the reentry tears) of true lumen and false lumen during systole and diastole for Case 1, Case 2 and Case 3. The arrows indicate the directions of the velocity vectors. Note: A is the true lumen region whereas B is the false lumen region. 
Accepted manuscript of an article published as: Naim, Wan and Ganesan, Poo and Sun, Zhonghua and Osman, Kahar and Lim, Einly. 2014. The impact of the number of tears in patient-specific Stanford type B aortic dissecting aneurysm: CFD simulation.

Journal of Mechanics in Medicine and Biology. 14 (2): 1450017 (20 p.). DOI: 10.1142/S0219519414500171

\subsection{Pressure Distribution}

Fig. 5 illustrates the pressure contour plot along the true lumen and false lumen for Case 1, 2 and 3 during the systolic and diastolic phase. Table 6 gives the range and mid values of pressure in the true and false lumen during the systolic and diastolic phase, at the three regions which are below the entry tear (A); above reentry tear 2 (B); and below reentry tear 1(C). For comparison, such results from Tse et al ${ }^{4}$ and Cheng et al ${ }^{21}$ are used. Pressure gradient decreases in the flow direction and this is consistent with the literature findings. The highest pressure of about $16.61 \mathrm{kPa}$ is in the aortic root for Cases 1, 2 and 3, while region of low pressure is at the descending aorta during systole. This pressure is relative to the outlet pressure of $15.69 \mathrm{kPa}$ at peak systole. Therefore the highest pressure difference between the inlet and the outlet is about $0.90 \mathrm{kPa}$

First, let us compare all cases during systole. The pressure in the true lumen is slightly higher than that in the false lumen at region $\mathrm{A}$, which is the proximal part of the dissection in all cases, with a difference around $0.20 \mathrm{kPa}$. At the region above reentry tear 2 (B), no significant pressure difference is observed between true and false lumen for Case 2 and 3. In contrast, in the absence of reentry tear 2 in Case 1, the pressure in the false lumen is approximately $0.20 \mathrm{kPa}$ higher than that in the true lumen. At region $\mathrm{C}$, which is the distal part of the vessel, the pressure in the false lumen is higher than that in the true lumen, with a difference of up to $1.00 \mathrm{kPa}$. Comparing the different cases, the largest difference occur in Case 1, with a difference magnitude of approximately 1.00 $\mathrm{kPa}$. The highest pressure is obtained at the region below reentry tear 1 (C) in the false lumen for Case $1(16.61 \mathrm{kPa})$.

As compared to the systolic phase, less significant difference is observed between pressure in the true and false lumens during diastole. Generally, the false lumen pressure is slightly higher than true lumen pressure throughout the aorta. The greatest difference occurs at the region below reentry tear 1 (C), with a magnitude of approximately 0.10 $\mathrm{kPa}$.

Table 6: Range and mid value of pressure in the true and false lumen during the systolic and diastolic phase, taken at (A) the region below the entry tear; (B) the region above reentry tear 2; and (C) the region below reentry tear 1.

\begin{tabular}{|c|c|c|c|c|c|c|c|c|c|}
\hline \multicolumn{2}{|c|}{ Case } & \multicolumn{4}{|c|}{ Systole (kPa) } & \multicolumn{4}{|c|}{ Diastole (kPa) } \\
\hline & & True lumen & & False lumen & & True lumen & & False lumen & \\
\hline & & Range & Mid & Range & Mid & Range & Mid & Range & Mid \\
\hline \multirow[t]{3}{*}{1} & $\mathrm{~A}$ & $16.52-16.70$ & 16.6 & $16.33-16.5$ & 16.4 & $14.30-14.3$ & 14.3 & $14.30-14.35$ & 14.33 \\
\hline & B & $16.12-16.33$ & 16.2 & $16.33-16.5$ & 16.4 & $14.43-14.5$ & 14.4 & $14.33-14.35$ & 14.34 \\
\hline & $\mathrm{C}$ & $15.60-15.78$ & 15.7 & $16.52-16.7$ & 16.6 & $14.13-14.4$ & 14.2 & $14.33-14.35$ & 14.34 \\
\hline \multirow[t]{3}{*}{2} & A & $16.52-16.70$ & 16.6 & $16.33-16.5$ & 16.4 & $14.28-14.3$ & 14.3 & $14.30-14.33$ & 14.32 \\
\hline & B & $16.33-16.52$ & 16.4 & $16.33-16.5$ & 16.4 & $14.33-14.4$ & 14.4 & $14.30-14.35$ & 14.33 \\
\hline & $\mathrm{C}$ & $15.60-15.78$ & 15.7 & $16.33-16.5$ & 16.4 & $14.15-14.4$ & 14.4 & $14.30-14.33$ & 14.32 \\
\hline \multirow[t]{3}{*}{3} & A & $16.52-16.70$ & 16.6 & $16.33-16.5$ & 16.4 & $14.28-14.3$ & 14.3 & $14.30-14.33$ & 14.32 \\
\hline & B & $16.33-16.52$ & 16.4 & $16.33-16.5$ & 16.4 & $14.33-14.4$ & 14.3 & $14.33-14.35$ & 14.34 \\
\hline & $\mathrm{C}$ & $15.60-15.78$ & 15.7 & $16.33-16.5$ & 16.4 & $14.08-14.4$ & 14.3 & $14.33-14.35$ & 14.34 \\
\hline
\end{tabular}


Accepted manuscript of an article published as: Naim, Wan and Ganesan, Poo and Sun, Zhonghua and Osman, Kahar and Lim, Einly. 2014. The impact of the number of tears in patient-specific Stanford type B aortic dissecting aneurysm: CFD simulation.

Journal of Mechanics in Medicine and Biology. 14 (2): 1450017 (20 p.). DOI: 10.1142/S0219519414500171

12 Wan Ab Naim, W.N. et al

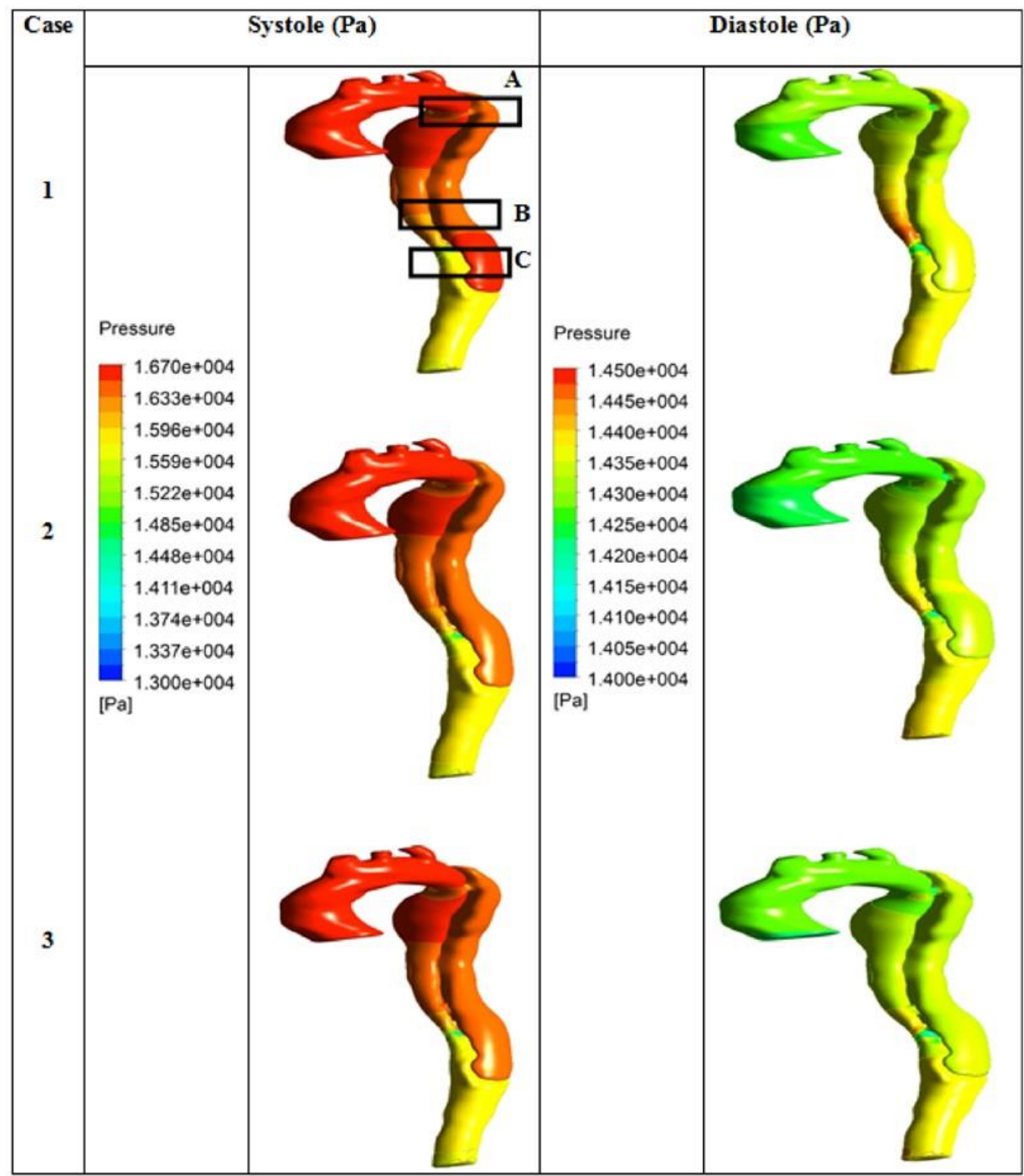

Fig. 5 : Pressure distribution along the true lumen and false lumen for case 1,2 and 3 during the systolic and diastolic phase. 


\subsection{Time average wall shear stress distribution (TAWSS)}

Time average wall shears stress (TAWSS) is presented to show the spatial variation of wall shear stress (WSS) ${ }^{34}$. The highest WSS is found at reentry tear 1 in all cases, i.e Case 1: 55.7-58.6 Pa; Case 2: 52.7-55.7 Pa; Case 3: 49.8 - 52.7 Pa during systole. During diastole, high WSS was also found around the reentry tear, 1 i.e Case 1: 14.6 -15.5 Pa; Case 2: 15.5 - 16.3 Pa; Case 3: 13.8-14.6 Pa. The WSS value during systole is higher as compared to that during diastole. Fig. 6 shows the contour plot of the TAWSS distribution along the true and false lumens in all cases. The highest TAWSS is found at reentry 1 in all cases i.e Case 1: 8.47-9.83 Pa; Case 2: 8.07 -8.97 Pa; Case 3: 7.52 - 8.35 $\mathrm{Pa}$. Other moderate and concentrated TAWSS regions can be observed at the posterior false lumen region at entry tear 1 and bottom part of reentry tear 2 (for Case $2 \& 3$ ). 
Accepted manuscript of an article published as: Naim, Wan and Ganesan, Poo and Sun, Zhonghua and Osman, Kahar and Lim, Einly. 2014. The impact of the number of tears in patient-specific Stanford type B aortic dissecting aneurysm: CFD simulation.

Journal of Mechanics in Medicine and Biology. 14 (2): 1450017 (20 p.). DOI: 10.1142/S0219519414500171

14 WanAb Nairn., W.N. etal

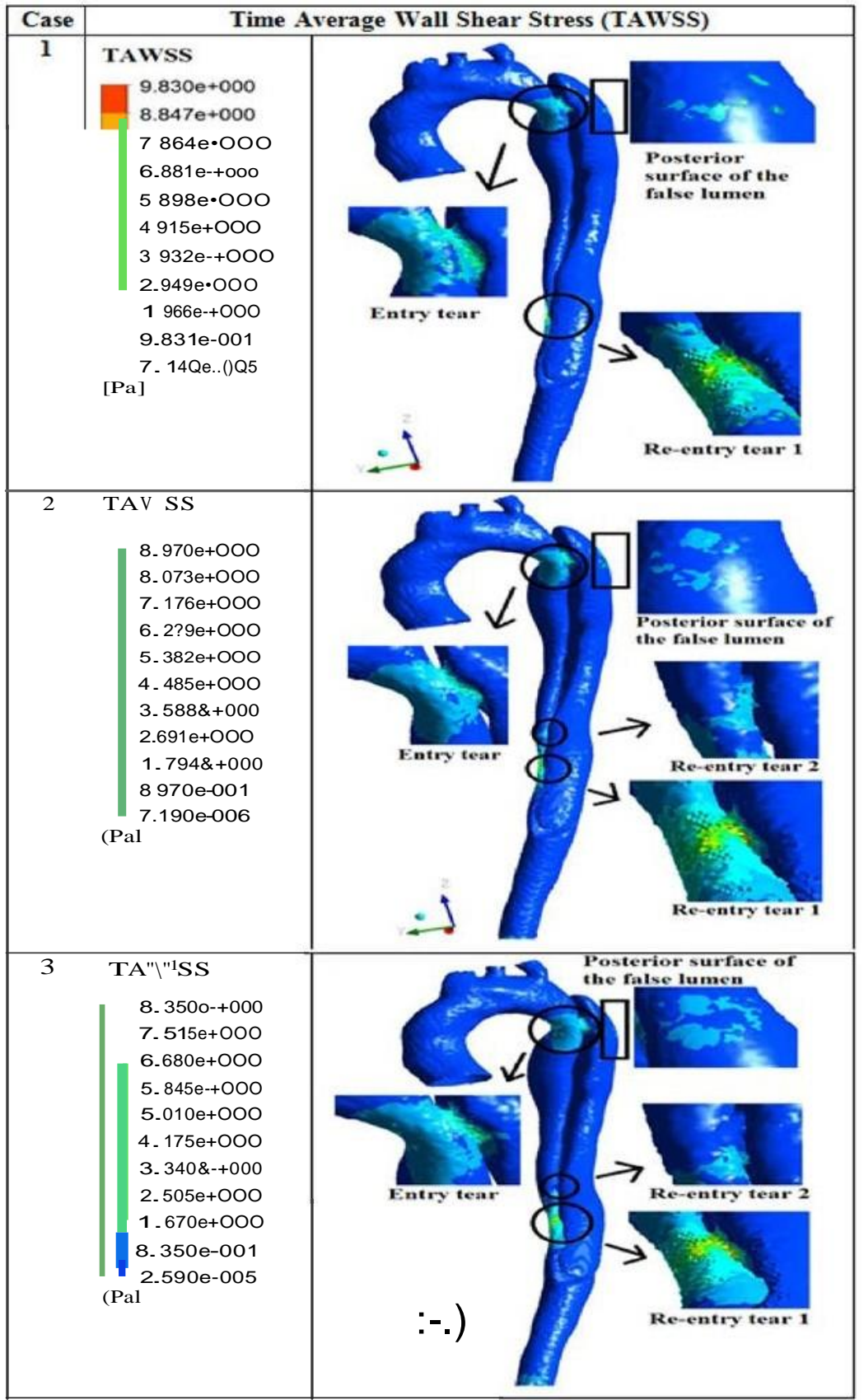

Fig. 6: Time average wall shear stress (TAWSS) distribution along the true and false lumen for Case I, 2 and 3 


\section{Discussion}

\subsection{Flow Distribution}

Our CFD simulation results showed that blood travels into the entry tear from the true lumen during systole with a high velocity in all cases and this is consistent with that reported in Cheng et al ${ }^{21}$ and Karmonik et al ${ }^{35}$. At the distal region, the blood returns to the true lumen through the reentry tears. High velocities were observed at the tear regions due to the narrow pathway provided by their small cross sectional areas. No flow separation observed during systole and this is consistent with findings by Siauw et $\mathrm{al}^{36}$

During diastole, the absolute magnitude of the flow velocity was reduced, leading to a change in the pressure distribution along the vessel. As compared to the systolic phase, directionally opposite blood flow occurs, where blood enters the false lumen through the reentry tears. Consequently, recirculation and retrograde flow patterns were observed in all cases, particularly adjacent to the posterior region of the proximal false lumen. This is consistent with published experimental and simulation results $3,21,35,37$. The changes of the cross sectional area from the small cross sectional area of the tear into the bigger area of false lumen region as well as the reducing of velocity during diastole causes the recirculation. This condition has been observed in the left ventricle studies by Khalafvand et al ${ }^{38,39}$ and in stenosis study by Cheung et al ${ }^{40}$. The recirculation flow rotates both in the clockwise and the counterclockwise direction, as reported in the experimental study by Wong et al ${ }^{23}$ and simulation study in the left ventricle by Khalafvand et al ${ }^{39}$. The aortic dissection geometry is complex due to the narrowing, dilation, and bending of the vessel ${ }^{21}$ The flow in the dissecting aneurysm may introduce recirculation as well the interaction between the blood and the wall. Recirculation has been reported to cause a deposition of the platelet ${ }^{41}$ that will result in the formation of thrombus.

The presence of an additional reentry tear as created in the current study, in overall, does not significantly change the direction of the blood pathway and the magnitude of the flow velocity. However, at the micro level, the extra reentry tear provides an extra return path for the blood to return to the true lumen during systole, and an extra outflow path into the false lumen during diastole. This investigation shows that the additional tear may give a detrimental effect at the diastolic phase by enhancing the flow to false lumen. On the other hand, it may give good effect at systolic phase by providing a pathway for the blood to return to the true lumen from the false lumen.

\subsection{Pressure Distribution}

Elevated false lumen pressure has frequently been associated with lumen expansion and rupture $^{3}$. Generally, pressure in the true lumen decreases along the flow direction, but lesser degree of variation exists for the false lumen ${ }^{3}$. Low pressure regions were observed near the reentry tears due to the coarctation of the tears. 
Our simulation results are consistent with those reported by Tse et al. ${ }^{4}$, who observed that while true lumen pressure was higher than false lumen pressure at the proximal region during systole, opposite phenomena occurred at the distal portion. Highest pressure difference between true and false lumen is obtained at the region below reentry tear 1 in the false lumen, which may cause further tear progression, false lumen rupture and collapse of the true lumen ${ }^{3}$

Based on an ex-vivo experimental study of chronic type B aortic dissection, Tsai et al. ${ }^{24}$ reported that the lack of distal tear results in a significant increase in the diastolic pressure due to an impairment of the outflow from the false lumen to the true lumen. Specifically, that study showed the increase of the pressure in the case of 2 tears and this is consistent with the finding in the current study. Similar findings were also reported by Karmonik et al. ${ }^{42}$ during systole in their simulation study, who found an increase in the pressure difference between true and false lumens in the absence of a reentry tear. Comparing with the different cases, our simulation results demonstrated the presence of an additional reentry tear not only decreases the false lumen pressure at the distal region during systole, but also reduced the pressure difference between the true and false lumens. Based on the previous findings ${ }^{24}, 2$ and our simulation results, the presence of an additional reentry tear increases the number of outflow from the false lumen back to the true lumen, thereby reduces the pressure at the distal region of the false lumen during systole. On the other hand, no significant difference is observed between cases 2 and 3 (with different reentry tear diameters) with regards to the pressure distribution in the true and false lumen, possibly due to the fact that the difference in tear sizes (37.5\%) between the two cases is not sufficient to cause a notable effect on the simulation results.

\subsection{Time average wall shear stress (TAWSS) Distribution}

In all cases, the highest TAWSS was found at reentry tear 1 due to high velocity at that region. The simulated TAWSS magnitude is higher than that reported for the normal arterial walls which is in the range of one to seven $\mathrm{Pa}{ }^{43}$, which may promote the extension and progression of the reentry tear. This finding is in line with Sheard et al. reported study. The endothelial cells are sensitive to changes in the wall shear stress ${ }^{19}$ and elevated levels of WSS may induce damage of the endothelium ${ }^{37}$. Elevated TAWSS has been associated with the extension of the tear in a post-aneurismal aorta model ${ }^{4}$ and is considered a reliable indicator of rupture in the case of abdominal aortic aneurysm (AAA) ${ }^{44}$. Based on the WSS values of the current study, hemolysis is unlikely to occur since the values are still below the critical WSS that has been reported by Hellums et al ${ }^{45}$.

On the other hand, moderately high concentrated TAWSS can be found at the posterior surface of the false lumen in all cases due to the impingement of jet flow passing through the entry tear region onto the posterior false lumen region. Similar findings have been reported in the literature ${ }^{3,21}$. As proposed by Rudenick et al ${ }^{3}$, slight increase in the TAWSS at the false lumen wall may lead to wall weakening and a subsequent increase in the lumen diameter, as false lumen only consists of the outer media and adventitia layer of the aortic wall ${ }^{10}$. 
Generally, with the presence of an additional reentry tear, no significant difference can be found with regards to TAWSS distribution as well as magnitude, except at regions adjacent to reentry tear 2. Moderate and concentrated TAWSS was observed at the bottom region of the reentry tear 2 in cases 2 and 3, which may lead to further extension of the tear distally, until it is connected to reentry tear 1 . On the contrary, low TAWSS was observed at the upper region of the reentry tear 2 for case 2 and case 3 due to low velocity at that region. As proposed by Borghi et al. ${ }^{46}$ and proven by Dake et al. ${ }^{15}$ in their study of AAA models, low TAWSS is associated with the formation and propagation of thrombus.

\subsection{Practical application or clinical value}

Endovascular stent grafting that covers the entry tears ${ }^{15}$ is being used as one of the effective treatment for type B aortic dissection. The purpose of the endovascular treatments is to induce the thrombus formation and close the false lumen. In 201 number of aortic dissection cases, 3 years mortality rate for patients with false lumen patency was $13.7 \pm 7.1 \%$, false lumen partial thrombosis was $31.6 \pm 12.4 \%$ and false lumen complete thrombosis was $22.6 \pm 22.6 \%{ }^{26}$. This shows that endovascular stent grafting treatment that try to form the thrombus in the false lumen shows high mortality compared to the patent false lumen. Tsai et al ${ }^{24}$ investigated the influence of covering entrance/exit tear on the pressure difference and the results showed that covering either the entry or reentry tear will results in significant increase of the pressure. Meanwhile, our results showed that the presence of three tears reduce the pressure compared to the two tears. Therefore, the use of the endovascular stent grafting that covers the tear in order to induce the thrombus formation needs to be considered if the covering will lead to the pressure increment and eventually cause aortic expansion and rupture.

In addition, one of the recently developed treatments for chronic aortic dissection is fenestration treatment. The concept of this treatment is to create a reentry tear for the dead-end false lumen and let the flow back into the true lumen with the aim of preventing thrombosis of the false lumen and relieve malperfusion syndromes from true lumen collapse ${ }^{22},{ }^{47}$. This concept is similar into our study, showing that presence of the tear will lead the flow back to the true lumen and increase of the tear will decrease pressure and finally prevent the false lumen expansion and reduce the possibility of the true lumen collapse. However, according to Nienaber et $\mathrm{al}^{47}$, this treatment is a lack of clinical proof and in long term there is a risk of rupture as a large reentry tear promotes flow in the false lumen and cause of the false lumen expansion. 


\subsection{Model limitations}

In the present study, the aortic wall was assumed to be rigid although it should be compliant in a real scenario. However, this is justified to be a reasonable assumption given the fact that the compliance of an aneurysmal blood vessel is significantly reduced due to the lack of elastin ${ }^{48}$. Furthermore, Boussel et al. ${ }^{48}$ found that no appreciable motion of the vessel wall over a cardiac cycle using cine images. In another study on aortic dissection, Karmonik et al ${ }^{42}$ also observed low intimal flap mobility through cine MRI images. The two-way transient fluid structure interaction (FSI) is considered valuable for investigation of the interaction of artery and blood ${ }^{49} 50$, and this will be studied in the future experiments. In addition, the flow was assumed to be laminar. This is based on similar approach used in Tse et al ${ }^{4}$, Lam et al ${ }^{29}$ and Morris et al ${ }^{30}$. It would be interesting to compare the results from laminar and turbulent flow cases, however, this will be considered in our future study.

Only one sample patient was selected in this study. This study provides the basic insight into the hemodynamic effect to the presence of the two and three tears in the aortic dissection case. Although different reentry tear location was simulated in this study, further research with inclusion of more patients with different aortic dissection configuration is needed to verify our models. Furthermore, this study can be further validated using the flow visualization using the clinical data ${ }^{51}$

\section{Conclusion}

Although the presence of an additional reentry tear neither changes the direction and magnitude of the blood flow, the extra reentry tear provides an extra return path for blood back to the true lumen during systole, and an extra outflow path into the false lumen during diastole. As a result, the false lumen pressure, particularly at the distal region, is decreased. The decrease of false lumen pressure is believed to minimize the risk of false lumen expansion. In terms of TAWSS distribution, no significant difference is found with the presence of an additional reentry tear, except at regions adjacent to reentry tear 2 . Moderate and concentrated TAWSS found at the bottom region of the additional reentry tear may cause further extension of the tear distally, leading to the fusion between the two reentry tears.

\section{Acknowledgments}

This study was funded by University Malaya Research Grant (RG109/11AET). 
Accepted manuscript of an article published as: Naim, Wan and Ganesan, Poo and Sun, Zhonghua and Osman, Kahar and Lim, Einly. 2014. The impact of the number of tears in patient-specific Stanford type B aortic dissecting aneurysm: CFD simulation.

Journal of Mechanics in Medicine and Biology. 14 (2): 1450017 (20 p.). DOI: 10.1142/S0219519414500171

\section{References}

1 Erbel R. et al. Diagnosis and management of aortic dissection. Europian Heart Journal 22: 1642-1681, 2001.

2 Coady MA, Rizzo JA, Goldstein LJ et al. Natural history, pathogenesis, and etilogy of thoracic aortic aneurysm and dissections. Cardiol Clin 17: 615, 1999.

3 Rudenick PA et al. A multi-method approach towards understanding the pathophysiology of aortic dissections- The complementary role of in-silico, in-vitro and in-vivo information.STACOM -CESC 2010,LNCS 6364. (ed O.Camara et al) 114-123 Springer, 2010

4 Tse KM, Chiu P, Lee HP, Ho P. Investigation of hemodynamics in the development of dissecting aneurysm within patient-specific dissecting aneurismal aortas using computational fluid dynamics (CFD) simulations. Journal of Biomechanics 44: 827-836, 2011.

5 Czermak BV. et al. Treatment of Stanford Type B aortic dissection with stent-grafts: Preliminary results. Radiology 217: 544-550, 2000.

6 LePage M, Quint LE, Sonnad SS, Deeb GM \& DM, W. Aortic Dissection: CT feautures that distinguish true from false lumen. AJR Am J Roentgenol 177: 207-211, 2001.

7 Williams DM, Lee DY, Hamilton BH \& al, e. The dissection aorta : Percutaneous treatment of ischemic complications - principles and results. J. Vasc Intervent Radiol 8: 605-625, 1997.

8 Kapoor V, Ferris JV \& CR., F. Intimomedial rupture : A new CT finding to distinguish true from false lumen in aortic dissection. AJR Am J Roentgenol 183, 2004.

$9 \quad$ Golledge J \& KA, E. Acute aortic dissection. Lancet 372: 55-66, 2008.

10 Karthikesalingam A, Holt PJE, Hinchliffe RJ, Thompson MM, Loftus, IM. The diagnosis and management of aortic dissection. Vasc Endovascular Surg 44(3): 165-169, 2010.

11 Pretre R \& K., V. S. L. Aortic dissection. Lancet 349: 1461-1464, 1997.

12 De Bakey ME, Henly WS, Cooley DA, Crawford ES, Morris, G C. Surgical treatment of dissecting aneurysm of the aorta analysis of seventy-two cases. Circulation 24: 290-303.' 1961.

13 Fattori $R$ et al. Malperfusion syndrome in type B aortic dissection : Role of the endovascular procedures. Acta Chir Belg 108: 192-197, 2008.

14 Trimarchi S. et al. Role and Results of Surgery in Acute Type B Aortic Dissection Insights From the International Registry of Acute Aortic Dissection (IRAD). Circulation.' 2006.

15 Dake MD et al. Endovascular stent-graft placement for the treatment of acute aortic dissection. The New England Journal of Medicine 340, 1999.

16 Thrumurthy SG, Karthikesalingam A, Patterson BO, Holt PJE, Thompson MM. The diagnosis and management of aortic dissection. BMJ 344, 2012.

17 Tsai,TT, Nienaber C.A, Eagle, K A. Acute aortic syndrome. Circulation 112: 38023813, 2005.

18 Toungara M, Chagnon G, Geindreau C. Numerical analysis of the wall stress in abdominal aortic aneurysm: influence of the material model near-incompressibility. Journal of mechanics in Medicine and Biology 12: 1250005-1250001-1250005-1250019, 2012.

19 Nabaei M, Fatouraee N. Computational modeling of formation of cerebral aneurysm under the influence of smooth muscle cell relaxation. Journal of Mechanics in Medicine and Biology 12: 1250006-1250001-1250006-1250018, 2012 
Accepted manuscript of an article published as: Naim, Wan and Ganesan, Poo and Sun, Zhonghua and Osman, Kahar and Lim, Einly. 2014. The impact of the number of tears in patient-specific Stanford type B aortic dissecting aneurysm: CFD simulation.

Journal of Mechanics in Medicine and Biology. 14 (2): 1450017 (20 p.). DOI: 10.1142/S0219519414500171

Wong KKL, Tu J Sun Z. Dissanayake, D. W. in Methods in Research and development of Biomedical Devices 119-116. World Scientific Publishing Co, 2013. Cheng $\mathrm{Z}$ et al. Analysis of flow patterns in a patient-specific aortic dissection model. Jounal of Biomechanical Engineering 132: 051007 -051001 - 051007 -051009 (2010). Wong KKL, Tu JY, RM, K. Vortical flow analysis. Journal of mechanics in Medicine and Biology 10: 191-212, 2010.

Wong KKL et al. Cardiac flow component analysis. Medical Engineering and Physics 32, 174-178, 2010.

Tsai TT, Schlicht MS, Khanafer K, Bull JL, Valassis DT, Williams DM, Berguer R, Eagle KA. Tear size and location impacts false lumen pressure in an ex vivo model of chronic type B aotic dissection. Journal of Vascular Surgery 47: 844-851, 2008.

Tang AYS, Fan Y, Cheng SWK, K.W. Biomechanical factors influencing tyep B thoracic aortic dissection : Computational fluid dynamics study. Engineering Applications of Computational Fluid Mechanics 6: 622-632, 2012.

Karmonik C et al. Computational study of haemodynamic effects of entry- and exit- tear coverage in a Debakey Type III aortic dissection : Technical report. Eur J Vasc Endovasc Surg 42: 172-177, 2011.

Quint, LE, Platt, JF, Sonnad SS, Deeb GM, Williams DM. Aortic intimal tears: Detection with spiral computed tomography. J Endovasc Ther 10: 505-510, 2003.

Wen CY, Yang AS, Tseng LY, Chai JW. Investigation of pulsatile flowfield in healthy thoracci aorta models. Annals of Biomedical Engineering 38: 391-402, 2010.

Lam SK, Fung SK, Cheng SWK, Chow KW. A computational study on the biomechanical factors related to stent graft models in the thoracic aorta. Med Biol Eng Comput 46: 1129-1138, 2008

Morris . et al. 3-D Numerical Simulation of blood flow through models of the human aorta. Journal of Biomechanical Engineering 127: 767-773, 2005.

Nerem R, Seed WA, Wood NB. An experimental study of the velocity distribution and transition to turbulence in the aorta. J Fluid MEch 52: 137-160, 1972.

Olufsen M S et al. Numerical simuation and experimental validation of blood flow in arteries with structured-tree outflow conditions. Annals of Biomedical Engineering 28: 1281-1299, 2000.

Shahcheraghi N, Dwyer HA, Cheer AY, Barakat AI, Rutaganira T. Unsteady and three dimensional simulation of blood flow in the human aotic ach. Journal of Biomechanical Engineering 124, 2002.

Tan FPP et al. Analysis of flow patterns in a patient-specific thoracic aortic aneurysm model. Computers and Structures 87: 680-690, 2009.

5. Karmonik $\mathrm{C}$ et al. Longitudinal computational fluid dynamics study of aneurysmal dilation in a chronic DeBakey type III aortic dissection. J Vasc Surg, 2012.

Siauw W, Ng EYK, Mazumdar J. Unsteady stenosis flow prediction : A comparative study of non-Newtonian models with operator splitting scheme. Medical Engineering \& Physics 22: 265-277, 2000

Sheard GJ. Flow dynamics and wall shear-stress variation in a fusiform aneurysm. $J$ Eng Math 64, 2009.

Khalafvand S, Ng EYK, Zhong L. CFD simulation of flow through heart: A perspective review. Computer Methods in Biomechanics and Biomedical Engineering 14: 113-132, 2011.

Khalafvand S, Ng EYK, Zhong L, Hung T. Fluid-dynamics modelling of the human left ventricle with dynamic mesh for normal and myocardial infarction: Preliminary study. Computers in Biology and Medicine 42: 863-870, 2012.

Cheung SC et al. Experimental and numerical study on the hemodynamics of stenosed carotid bifurcation. Australas Phys Eng Sci Med 33: 319-328, 2010 
Bluestein D, Guteierrez C, Londono M, Schoephoerster RT. Vortex shedding in steady flow through a model of an arterial stenosis and its relevance to mural platelet deposition. Annals of Biomedical Engineering 27: 763-773, 1999.37 Papaioannou

$\mathrm{T}$, Stefanadis C. Vascular wall shear stress : basic pinciples and methods. Hellenic J Cardiol 46: 9-15, 2005.

42 Karmonik $\mathrm{C}$ et al. in 32nd Annual International Conference of the IEEE EMBS. Buenos Aires, Argentina, 2010.

43 Papaioannou T, Stefanadis C. Vascular wall shear stress : Basic pinciples and methods. Hellenic J Cardiol 46: 9-15, 2005.

$44 \mathrm{Xu}$ XY et al. High levels of 18F-FDG uptake in aortic aneurysm wall are associated with high wall stress. Eur J Vasc Endovasc Surg 39: 295-301, 2010.

45 Hellums JD. 1993 Whitaker lecture : Biorheology in thrombosis research. Annals of Biomedical Engineering 22: 445-455, 1994

46 Borghi A, Wood NB, Mohiaddin RH, Xua, XY. Fluid-solid interaction simulation of flow and stress pattern in thoracoabdominal aneurysms : A patient-specific study. Journal of Fluids and Structures 24: 270-280, 2008.

47 Nienaber CA, Eagle KA. Aortic dissection: New frontiers in diagnosis amd management : Part II : Therapeutic management and follo-up. Circulation 108: 772-778, 2003.

48 Boussel L, Rayz V, Martin A, Acevedo-Bolton G, Lawton MT, Higashida R, Smith WS, Young WL, Saloner D. Phase-contrast MRI measurements in intra-cranial aneurysms invivo of flow patterns, velocity field and wall shear stress : A comparison with CFD. Magn Reson Med 61: 409-417, 2009

49 Wong KKL, Thavornpattanapong P, Cheung SC, Sun Z, Tu J. Effect of calcification on the mechanical stability of plaque based on a three-dimensional carotid bifurcation model. BMC Cardiovascular Disorders 12, 2012.

50 Wong, KKL, Thavornpattanapong, P, Cheung, SC, Yu J. Biomechanical investigation of pulsatile flow in a three-dimensional atherosclerotic carotid bifurcation model. Journal of mechanics in Medicine and Biology 13: 1-21, 2013.

51 Wong KKL, Kuklik P, Worthley SG and Sanders P. Flow Analysis. International (PCT) Patent Application PCT/AU/2007/000827, 2007 
Accepted manuscript of an article published as: Naim, Wan and Ganesan, Poo and Sun, Zhonghua and Osman, Kahar and Lim, Einly. 2014.

The impact of the number of tears in patient-specific Stanford type B aortic dissecting aneurysm: CFD simulation.

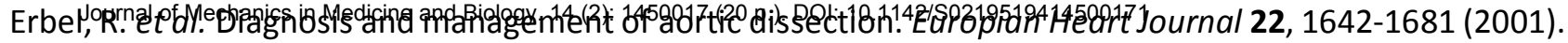
Coady MA, Rizzo JA, Goldstein L \& al, e. Natural history, pathogenesis, and etilogy of thoracic aortic aneurysm and dissections. Cardiol Clin 17, 615 (1999).

Paula A. Rudenick et al. in STACOM -CESC 2010,LNCS 6364. (ed O.Camara et al) 114-123 (Springer).

Kwong Ming Tse, Peixuan Chiu, HEow Pueh Lee \& Ho, P. Investigation of hemodynamics in the development of dissecting aneurysm within patient-specific dissecting aneurismal aortas using computational fluid dynamics (CFD) simulations. Journal of Biomechanics 44, 827-836 (2011).

Czermak, B. V. et al. Treatment of Stanford Type B aortic dissection with stent-grafts: Preliminary results. Radiology 217, 544-550 (2000). LePage M, Quint LE, Sonnad SS, Deeb GM \& DM, W. Aortic Dissection: CT feautures that distinguish true from false lumen. AJR Am J Roentgenol 177, 207-211 (2001). Williams DM, Lee DY, Hamilton BH \& al, e. The dissection aorta : Percutaneous treatment of ischemic complications - principles and results. J. Vasc Intervent Radiol 8, 605-625 (1997). Kapoor V, Ferris JV \& CR., F. Intimomedial rupture : A new CT finding to distinguish true from false lumen in aortic dissection. AJR Am J Roentgenol 183 (2004). Golledge, J., \& Eagle, K.A. Acute aortic dissection. Lancet 372, 55-66 (2008). Karthikesalingam, A., Holt, P. J. E., R.J. Hinchliffe, Thompson, M. M. \& Loftus, I. M. The diagnosis and management of aortic dissection. Vasc Endovascular Surg 44, 165-169 (2010). Pretre, R., \& Von Segesser, L.K. Aortic dissection. Lancet 349, 1461-1464 (1997). Michael E. De Bakey, Walter S. Henly, Denton A. Cooley, E. Stanley Crawford \& Morris, G. C. Surgical treatment of dissecting aneurysm of the aorta analysis of seventy-two cases. Circulation 24, 290-303 (1961).

R. Fattori et al. Malperfusion syndrome in type B aortic dissection : Role of the endovascular procedures. Acta Chir Belg 108, 192-197 (2008). Trimarchi, S. et al. Role and Results of Surgery in Acute Type B Aortic Dissection Insights From the International Registry of Acute Aortic Dissection (IRAD). Circulation (2006). Dake, M. D. et al. ENDOVASCULAR STENT-GRAFT PLACEMENT FOR THE TREATMENT OF ACUTE AORTIC DISSECTION. The New England Journal of Medicine 340 (1999). Thrumurthy, S. G., Karthikesalingam, A., Patterson, B.O., Holt, P.J.E., \& Thompson, M.M. The diagnosis and management of aortic dissection. BMJ 344 (2012). Tsai, T. T., Nienaber, C. A. \& Eagle, K. A. Acute aortic syndrome. Circulation 112, 3802-3813 (2005). Mamadou Toungara, Gregory Chagnon \& Geindreau, C. Numerical analysis of the wall stress in abdominal aortic aneurysm: influence of the material model near-incompressibility. Journal of mechanics in Medicine and Biology 12, 1250005-1250001-1250005-1250019 (2012).

19 Nabaei, M. \& Fatouraee, N. Computational modeling of formation of cerebral aneurysm under the influence of smooth muscle cell relaxation. Journal of Mechanics in Medicine and Biology 12, 1250006-1250001-12500061250018 (2012).

20 Wong, K. K. L., Tu, J., Sun, Z. \& Dissanayake, D. W. Methods in Research and development of Biomedical Devices. (World Scientific Publishing Co, 2013).

21 Z. Cheng et al. Analysis of flow patterns in a patient-specific aortic dissection model. Jounal of Biomechanical Engineering 132, 051007 -051001 - 051007 -051009 (2010).

22 Wong KKL, Tu JY \& RM, K. Vortical flow analysis. Journal of mechanics in Medicine and Biology 10, 191-212 (2010).

23 Kelvin K.L. Wong et al. Cardiac flow component analysis. Medical Engineering and Physics 32, 174-178 (2010).

24 Tsai, T. T., Schlicht, M.S., Khanafer, K., Bull, J.L., Valassis, D.T., Williams, D.M., Berguer, R., \& Eagle, K.A. Tear size and location impacts false lumen pressure in an ex vivo model of chronic type B aotic dissection. Journal of Vascular Surgery 47, 844-851 (2008).

25 A.Y.S. Tang, Y. Fan, S.W.K. Cheng \& K.W. Biomechanical factors influencing tyep B thoracic aortic dissection : Computational fluid dynamics study. Engineering Applications of Computational Fluid Mechanics 6, 622-632 (2012). Type III aortic dissection : Technical report. Eur J Vasc Endovasc Surg 42, 172-177 (2011). LE, Q., JF, P., SS, S., GM, D. \& DM, W. Aortic intimal tears: Detection with spiral computed tomography. J Endovasc Ther 10, 505-510 (2003). 
Accepted manuscript of an article published as: Naim, Wan and Ganesan, Poo and Sun, Zhonghua and Osman, Kahar and Lim, Einly. 2014.

The impact of the number of tears in patient-specific Stanford type B aortic dissecting aneurysm: CFD simulation.

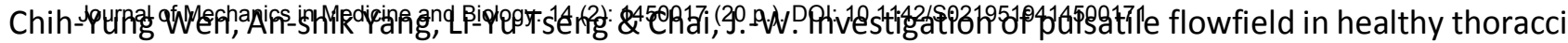
aorta models. Annals of Biomedical Engineering 38, 391-402 (2010). S. K. Lam, George S. K. Fung, Stephen W. K. Cheng \& Chow, K. W. A computational study on the biomechanical factors related to stent graft models in the thoracic aorta. Med Biol Eng Comput 46, 1129-1138 (2008). Morris, L. et al. 3-D Numerical Simulation of blood flow through models of the human aorta. Journal of Biomechanical Engineering 127, 767-773 (2005).

31 Nerem, R., WA, S. \& NB, W. An experimental study of the velocity distribution and transition to turbulence in the aorta. J Fluid MEch 52, 137-160 (1972). Olufsen, M. S. et al. Numerical simuation and experimental validation of blood flow in arteries with structuredtree outflow conditions. Annals of Biomedical Engineering 28, 1281-1299 (2000). Shahcheraghi, N., Dwyer, H.A., Cheer, A.Y., Barakat, A.I., \& Rutaganira, T. Unsteady and three dimensional simulation of blood flow in the human aotic ach. Journal of Biomechanical Engineering 124 (2002). F.P.P. Tan et al. Analysis of flow
Structures 87, 680-690 (2009). Christof Karmonik et al. Longitudinal computational fluid dynamics study of aneurysmal dilation in a chronic DeBakey type III aortic dissection. J Vasc Surg (2012). Siauw, W., Ng, E. \& Mazumdar, J. Unsteady stenosis flow prediction : A comparative study of non-Newtonian models with operator splitting scheme. Medical Engineering \& Physics 22, 265-277 (2000). Sheard, G. J. Flow dynamics and wall shear-stress variation in a fusiform aneurysm. J Eng Math 64 (2009). Khalafvand, S., Ng, E. \& Zhong, L. CFD simulation of flow through heart: A perspective review. Computer Methods in Biomechanics and Biomedical Engineering 14, 113-132 (2011). Khalafvand, S., Ng, E., Zhong, L. \& Hung, T. Fluid-dynamics modelling of the human left ventricle with dynamic mesh for normal and myocardial infarction: Preliminary study. Computers in Biology and Medicine 42, 863-870 (2012).

Cheung, S. C. et al. Experimental and numerical study on the hemodynamics of stenosed carotid bifurcation. Australas Phys Eng Sci Med 33, 319-328 (2010).

41 Bluestein D, Guteierrez C, Londono M \& RT, S. Vortex shedding in steady flow through a model of an arterial stenosis and its relevance to mural platelet deposition. Annals of Biomedical Engineering 27, 763-773 (1999). Christof Karmonik et al. in 32nd Annual International Conference of the IEEE EMBS (Buenos Aires, Argentina, 2010).

43 Papaioannou, T., \& Stefanadis, C. Vascular wall shear stress : basic pinciples and methods. Hellenic J Cardiol 46, 9-15 (2005).

44 X.Y. Xu et al. High levels of 18F-FDG uptake in aortic aneurysm wall are associated with high wall stress. Eur J Vasc Endovasc Surg 39, 295-301 (2010).

45 Hellums JD. 1993 Whitaker lecture : Biorheology in thrombosis research. Annals of Biomedical Engineering 22, 445-455 (1994).

46 A. Borghi, N.B. Wood, R.H. Mohiaddin \& Xua, X. Y. Fluid-solid interaction simulation of flow and stress pattern in thoracoabdominal aneurysms : A patient-specific study. Journal of Fluids and Structures 24, 270-280 (2008).

47 Nienaber, C. A., \& Eagle, K.A. Aortic dissection: New frontiers in diagnosis amd management : Part II : Therapeutic management and follo-up. Circulation 108, 772-778 (2003).

48 Boussel, L., Rayz, V., Martin, A., Acevedo-bolton, G., Lawton, M.T., Higashida, R., Smith, W.S., Young, W.L., \& Saloner, D. Phase-contrast MRI measurements in intra-cranial aneurysms in-vivo of flow patterns, velocity fields and wall shear stress : A comparison with CFD. Magn Reson Med 61, 409-417 (2009).

49 Wong, K. K., Thavornpattanapong, P., Cheung, S. C., Sun, Z. \& Tu, J. Effect of calcification on the mechanical stability of plaque based on a three-dimensional carotid bifurcation model. BMC Cardiovascular Disorders 12 (2012).

50 Wong, K. K., Thavornpattanapong, P., Cheung, S. C. \& Yu, J. Biomechanical investigation of pulsatile flow in a three-dimensional atherosclerotic carotid bifurcation model. Journal of mechanics in Medicine and Biology 13, 121 (2013).

51 Wong, K. K., Kuklik, P., Worthley, S. \& Sanders, P. Flow analysis. (2008). 